This is an open access article distributed under the terms of the Creative Commons BY-NC-ND Licence

\title{
Effects of methyl jasmonate on growth, antioxidants, and carbon and nitrogen metabolism of Glycyrrhiza uralensis under salt stress
}

\author{
X. YU ${ }^{1}$, P. FEI $I^{3}$, Z. XIE ${ }^{1}$, W. ZHANG ${ }^{1}$, Q. ZHAO ${ }^{1 *}$, and X. ZHANG ${ }^{1,2 *}$ \\ College of Pharmacy, Ningxia Medical University, Yinchuan 750004, P.R. China ${ }^{1}$ \\ Key Laboratory of Hui Ethnic Medicine Modernization, Ministry of Education, Ningxia Medical \\ University, Yinchuan 750004, P.R. China ${ }^{2}$ \\ Department of Pharmacy, General Hospital of Ningxia Medical University, Yinchuan 750004, P.R. China ${ }^{3}$
}

\begin{abstract}
We investigated the effects of 0.025 or $0.05 \mathrm{mM}$ methyl jasmonate (MeJA) on the growth characteristics, antioxidant enzyme activities, non-enzymatic antioxidant content, and carbon and nitrogen metabolizing enzyme activities in Glycyrrhiza uralensis exposed to $100 \mathrm{mM} \mathrm{NaCl}$. Results showed that salt stress decreased the stem length and lateral root number and the treatment with 0.025 or $0.05 \mathrm{mM} \mathrm{MeJA}$ increased the root length of salt-stressed G. uralensis seedlings but decreased root diameter, stem length, and stem diameter. MeJA application modulated oxidative stress in salt-stressed G. uralensis seedlings. It decreased the catalase activity but enhanced peroxidase activity and ascorbate content. However, treatment with $0.05 \mathrm{mM}$ MeJA significantly increased the malondialdehyde content of salt-stressed seedlings. Salt stress inhibited carbon and nitrogen metabolism. The application of MeJA enhanced the activities of sucrose synthase, and sucrose phosphate synthase, and nitrate reductase in salt-stressed seedlings.
\end{abstract}

Additional key words: ascorbate, catalase, $\mathrm{H}_{2} \mathrm{O}_{2}$, malondialdehyde, nitrate reductase, peroxidase, sucrose synthase, superoxide dismutase.

\section{Introduction}

Glycyrrhiza uralensis Fisch. is a member of an ancient legume family native to Asia. The genus Glycyrrhiza comprises 18 wild and cultivated species. The Chinese licorice (G. uralensis) is widely used as a herbal medicine (Pan et al. 2006) and its main active compounds exhibit anticancer, antiviral, anti-inflammatory, and immunoregulative properties (Schrofelbauer et al. 2009).

Salinity is one of the most severe problems of agriculture worldwide, especially in arid and semi-arid regions. High salt concentrations can impair growth and physiological activities of plants by inducing osmotic stress, ionic stress, or a combination of these stresses (Zhang et al. 2008, Slama et al. 2015). Wild G. uralensis possesses the excellent resistance to cold, heat, drought, and salinity. Nevertheless, high salt concentration remains an important factor that affects the growth and quality of cultivated G. uralensis. Pan et al. (2006) stated that the growth and metabolism of $G$. uralensis are negatively affected by $1.5 \%(\mathrm{~m} / \mathrm{v}) \mathrm{NaCl}$ and some of physiological and biochemical indexes are abnormal under $2 \% \mathrm{NaCl}$ stress. Yang et al. (2006) found that the maximum $\mathrm{NaCl}$ concentration that $G$. uralensis can tolerate ranges from 100 to $200 \mathrm{mM}$.

The production of reactive oxygen species (ROS) is one of the main responses of plants to salt stress (Eraslan et al. 2007). Excessive amounts of ROS, such as hydrogen peroxide and superoxide radicals, can first enhance membrane lipid peroxidation and damage of chloroplasts,

Submitted 31 October 2017, last revision 19 June 2018, accepted 20 June 2018.

Abbreviations: ABA - abscisic acid; AsA - ascorbic acid; CAT - catalase; GS - glutamine synthetase; MDA - malondialdehyde; MeJA - methyl jasmonate; NR - nitrate reductase; $\mathrm{O}_{2}{ }^{--}$- superoxide anion; POD - peroxidase; PR - pathogenesis-related; ROS - reactive oxygen species; SOD - superoxide dismutase; SPS - sucrose phosphate synthase; SS - sucrose synthase.

Acknowledgements: The authors are grateful for the financial support provided by the project of the National Natural Science Foundation of China (No. 31460330) and Key National Research and Development Programs (No. 2017YFC1700706). The first two authors equally contributed to the manuscript.

* Corresponding authors; e-mails: zhang2013512@163.com; 25136659@qq.com 
then inhibit photochemical reactions and reduce photosynthesis (Gunes 2007). Abdelhamid et al. (2015) observed that salinity induces oxidative stress in Phaseolus vulgaris plants by promoting ROS production. Wutipraditkul et al. (2015) demonstrated that salt stress causes oxidative stress in rice seedlings by increasing $\mathrm{H}_{2} \mathrm{O}_{2}$ content. Pan et al. (2006) found that salt stress stimulates oxidative stress in $G$. uralensis seedlings by elevating lipid peroxidation. Salt stress also changes carbon and nitrogen metabolism in plants. Salt stress inhibits carbon metabolism by affecting photosynthesis, consequently decreasing the energy available for biomass production. The regulation of nitrogen metabolism is crucial for salt tolerance, and the highly complex interaction between salinity and nitrogen nutrition affects almost all plant processes. Wang et al. (2012) showed that salt stress negligibly influences the accumulation of ammonium nitrogen in young rice leaves and drastically stimulates ammonium nitrogen accumulation in old rice leaves.

Methyl jasmonate (MeJA) is an important phytohormone that participates in diverse processes, such as seed germination, root growth, gravitropism, trichome formation, embryonic development, seedling development, tuber formation, leaf movement, fruit ripening, and leaf senescence (Wasternack and Hause 2002, Wasternack et al. 2014, Gumerova et al. 2015). Exogenous MeJA may be involved in the plant response to salinity and water stress (Kang et al. 2005). MeJA triggers the reprogramming of gene expression, which allows plant cells to adapt to insect-driven wounding, pathogen attack, and environmental stresses, including drought, low temperature, and salinity (Wolucka and Goossens 2005).

\section{Materials and methods}

Seed germination: Glycyrrhiza uralensis Fisch. seeds were obtained from wild plants in the Ningxia Hui Autonomous Region, China, in August 2015. The seeds were steeped with $85 \%(\mathrm{~m} / \mathrm{v}) \mathrm{H}_{2} \mathrm{SO}_{4}$ for $2.5 \mathrm{~h}$, then surface sterilized with $0.1 \%(\mathrm{v} / \mathrm{v}) \mathrm{H}_{2} \mathrm{O}_{2}$ for $10 \mathrm{~min}$, rinsed three-times in distilled water, and imbibed in distilled water at $4{ }^{\circ} \mathrm{C}$ for $12 \mathrm{~h}$. Then, 50 seeds were sown in Petri dishes $(95 \times 15 \mathrm{~mm})$ with two layers of Whatman No. 2 filter paper (Runyan Technology, Yin chuan, P.R. China). Treatments included application of 0.025 or $0.05 \mathrm{mM}$ MeJA in combination with $100 \mathrm{mM} \mathrm{NaCl}$ and control (CK) with distilled water alone. MeJA was dissolved in a small amount of Tween 20 and purchased as a $95 \%(\mathrm{~m} / \mathrm{v})$ aqueous solution. Germination experiments were carried out in an incubator maintained at day/night temperatures of $28 / 20{ }^{\circ} \mathrm{C}$ in the dark. We considered germination to have occurred when the radicle had emerged by at least $1.0 \mathrm{~mm}$. The number of germinated seeds was recorded every day. After growing for $10 \mathrm{~d}$, length of stems and roots, diameter of main stems and main roots were
The application of MeJA to non-stressed and stressed Artemisia annua and strawberry plants enhances antioxidant enzyme activities, including those of catalase (CAT), peroxidase (POD), and superoxide dismutase (SOD), thus improving the ROS scavenging mechanism of the treated plants (Tariq et al. 2011, Faghih et al. 2017). MeJA decreases ion concentration and ROS content and increases antioxidant enzyme activities to alleviate salt stress in Robinia pseudoacacia (Jiang et al. 2016). In salinity-stressed rice, the application of MeJA modifies the content of abscisic acid (ABA) and diminishes the inhibitory effect of salt stress on photosynthetic rate (Kang et al. 2005, Walia et al. 2006). Ji et al. (2009) found that MeJA treatment counteracts the negative effects of salt stress on the growth, chlorophyll content, leaf photosynthetic rate, leaf transpiration rate, and proline content of soybean plants grown in a hydroponic medium. MeJA induces the expression of pathogenesis-related proteins (PR), such as PR-1 and PR-10, and salt-stress responsive protein in the roots of rice plants to combat stress (Moons et al. 1997). Furthermore, MeJA can affect the whole-plant resource allocation of nitrogen- and carbon-containing substrates under stress (Gómez et al. 2010). These studies clearly demonstrated that exogenous MeJA can effectively alleviate the detrimental effects of salt stress on plants. This effect and its underlying mechanism vary across plant species. However, the application of MeJA on G. uralensis seedlings under salt stress has not been reported. The present work was conducted to study the effects of MeJA on the growth, antioxidant system, and carbon and nitrogen metabolism of salt-stressed $G$. uralensis seedlings.

recorded. Each treatment was replicated four times, the whole experiment was repeated twice.

Antioxidants and lipid peroxidation: Fresh shoot and root samples $(0.5 \mathrm{~g})$ were homogenized at $4^{\circ} \mathrm{C}$ in $8 \mathrm{~cm}^{3}$ of extraction buffer $[50 \mathrm{mM}$ phosphate buffer $(\mathrm{pH} 7.0)$ containing $1 \mathrm{mM}$ ascorbic acid (AsA), $1 \mathrm{mM}$ dithiothreitol (DTT), $1 \mathrm{mM}$ glutathione (GSH), and $1 \mathrm{mM} \mathrm{MgCl}_{2}$ ] with mortar and pestle. The homogenate was then centrifuged at $4000 \mathrm{~g}$ for $20 \mathrm{~min}$ and was used for determination of catalase (CAT) and peroxidase (POD) activities and malondialdehyde (MDA) and ascorbate (AsA) content.

The CAT activity was assayed, according to Sohn et al. (2005) with minor modifications. The CAT reaction solution comprised $50 \mathrm{mM}$ phosphate buffer $(\mathrm{pH} 7.8)$, $100 \mathrm{mM} \mathrm{H}_{2} \mathrm{O}_{2}$, and $0.1 \mathrm{~cm}^{3}$ of enzyme extract. Changes in the absorbance of the reaction solution at $240 \mathrm{~nm}$ were recorded for $5 \mathrm{~min}$.

The POD activity was assayed according to Pan et al. (2006) with minor modifications. The enzyme extract $(0.2$ 
$\mathrm{cm}^{3}$ ) was mixed with $2.7 \mathrm{~cm}^{3}$ of $50 \mathrm{mM}$ phosphate buffer (pH 7.8), $0.1 \mathrm{~cm}^{3}$ of $50 \mathrm{mM}$ of guaiacol, and $1 \mathrm{~cm}^{3}$ of $2 \%$ $(\mathrm{v} / \mathrm{v}) \mathrm{H}_{2} \mathrm{O}_{2}$ and the change in absorbance was measured at $470 \mathrm{~nm}$ for $5 \mathrm{~min}$.

The AsA content was determined according to Li et al. (2015) using $0.2 \mathrm{~g}$ of fresh tissue. Standards for AsA was prepared in the range of $0-15 \mathrm{mg} \mathrm{dm}^{-3}$ in $1 \mathrm{~cm}^{3}$ of $5 \%$ $(\mathrm{m} / \mathrm{v})$ trichloroacetic acid (TCA), $1 \mathrm{~cm}^{3}$ of ethanol, $0.5 \mathrm{~cm}^{3}$ of $0.4 \%(\mathrm{~m} / \mathrm{v}) \quad \mathrm{H}_{3} \mathrm{PO}_{4}, 1 \mathrm{~cm}^{3}$ of $0.5 \%$ bathophenanthroline (BP), and $0.5 \mathrm{~cm}^{3}$ of $0.03 \%(\mathrm{~m} / \mathrm{v})$ $\mathrm{FeCl}_{3}$ at $30{ }^{\circ} \mathrm{C}$ for $90 \mathrm{~min}$ and measured at $534 \mathrm{~nm}$. For each sample AsA was estimated as above.

Membrane lipid peroxidation was determined by measuring the MDA content using the method of Zhou et al. (2004) with minor modifications. The enzyme extract $\left(1 \mathrm{~cm}^{3}\right)$ was mixed with $2.5 \mathrm{~cm}^{3}$ of $0.5 \%(\mathrm{~m} / \mathrm{v})$ thiobarbituric acid (TBA) and then was heated at $100{ }^{\circ} \mathrm{C}$ for $20 \mathrm{~min}$. The absorbance was determined at 450, 532, and $600 \mathrm{~nm}$ respectively.

Determination of superoxide anion production and $\mathrm{H}_{2} \mathrm{O}_{2}$ content: For the extraction of superoxide radical $\left(\mathrm{O}_{2}^{-}\right)$, ascorbate and glutathione (reduced and oxidized), $1 \mathrm{~g}$ of the tissue from control and stressed plants were ground in $5 \mathrm{~cm}^{3}$ of chilled $0.8 \mathrm{M} \mathrm{HClO}_{4}$ and centrifuged at $10000 \mathrm{~g}$ for $25 \mathrm{~min}$. The clear supernatant was decanted carefully and $\mathrm{O}_{2}^{-}$was measured by monitoring the nitrite formation from hydroxylamine following the method of (Chawla et al. 2013). Amount of $\mathrm{NO}_{2}{ }^{-}$formed which corresponded to $\mathrm{O}_{2}^{-}$production was calculated from standard curve.

$\mathrm{H}_{2} \mathrm{O}_{2}$ was extracted by homogenizing $4 \mathrm{~g}$ tissue in $5 \mathrm{~cm}^{3}$ of ice cold $0.01 \mathrm{M}$ phosphate buffer ( $\mathrm{pH} \mathrm{7.0)}$ and centrifuging the homogenate at $8000 \mathrm{~g}$ for $10 \mathrm{~min}$. The supernatant was added to $1.95 \mathrm{~cm}^{3}$ of $0.01 \mathrm{M}$ phosphate buffer ( $\mathrm{pH} \mathrm{7.0)}$. To the mixture, $2 \mathrm{~cm}^{3}$ of $5 \%(\mathrm{~m} / \mathrm{v})$ potassium dichromate and glacial acetic acid (1:3, v/v) was added. The absorbance was read at $570 \mathrm{~nm}$ against the reagent blank without sample extract (Chawla et al. 2013).

Carbon and nitrogen metabolism: Fresh shoots and roots $(0.5 \mathrm{~g})$ were homogenized at $4{ }^{\circ} \mathrm{C}$ in $3 \mathrm{~cm}^{3}$ of extraction buffer $[100 \mathrm{mM}$ Tris- $\mathrm{HCl}$ buffer $(\mathrm{pH} 7.2)$ containing $10 \mathrm{mM} \mathrm{MgCl} 2,1 \mathrm{mM}$ EDTA-Na $2,10 \mathrm{mM}$ $\beta$-hydrophobic base ethanol, $2 \%$ (v/v) ethylene glycol, and $1 \%(\mathrm{~m} / \mathrm{v})$ polyvinyl pyrrolidone] with mortar and pestle. The homogenate was then centrifuged at $12000 \mathrm{~g}$ for $10 \mathrm{~min}$ and the supernatant was used for determination of sucrose synthase (SS) and sucrose phosphate synthase (SPS) activities by the method described by Zhang et al. (2017). For SS activity, reaction mixtures contained 100 $\mathrm{mM}$ Tris- $\mathrm{HCl}$ buffer ( $\mathrm{pH} 7.2$ ), $10 \mathrm{mM} \mathrm{MgCl}_{2}, 5 \mathrm{mM}$ uridine diphosphate glucose (UDPG), $5 \mathrm{mM}$ fructose, and the $0.3 \mathrm{~cm}^{3}$ of sample. For SPS activity, $5 \mathrm{mM}$ fructose was substituted for $5 \mathrm{mM}$ fructose-6-phosphate.

For the nitrate reductase (NR) activity assay, approximately $0.5 \mathrm{~g}$ samples of fresh tissue were ground in a prechilled mortar and pestle on ice in $4 \mathrm{~cm}^{3}$ of extraction buffer. The extraction $25 \mathrm{mM}$ buffer ( $\mathrm{pH} 8.7$ ) contained $10 \mathrm{mM}$ cysteine and $1 \mathrm{mM}$ EDTA. The mixture was centrifuged at $4000 \mathrm{~g}$ and $4{ }^{\circ} \mathrm{C}$ for $15 \mathrm{~min}$ and then $0.5 \mathrm{~cm}^{3}$ of supernatant was added to the reaction mixture. The reaction mixture comprised of $1.2 \mathrm{~cm}^{3}$ of $100 \mathrm{mM}$ $\mathrm{KNO}_{3}$-phosphate buffer (pH 7.5) and incubated at $25^{\circ} \mathrm{C}$ for $30 \mathrm{~min}$. The reaction was terminated by adding $1 \mathrm{~cm}^{3}$ of $1 \%(\mathrm{~m} / \mathrm{v})$ sulfanilamide in $3 \mathrm{M} \mathrm{HCl}$. For nitrite determination, $1 \mathrm{~cm}^{3}$ of $0.02 \%(\mathrm{~m} / \mathrm{v})$ N-naphthyl-(1)dihydrochloride was added, and the colour was allowed to develop at $25^{\circ} \mathrm{C}$ for $15 \mathrm{~min}$. The mixture was centrifuged at $4000 \mathrm{~g}$ and $4{ }^{\circ} \mathrm{C}$ for $5 \mathrm{~min}$, and then the absorbance of the supernatant at $540 \mathrm{~nm}$ was measured (Yang et al. 2014).

To measure glutamine synthetase (GS) activity freshly harvested shoots and roots were ground on ice in an extraction Tris-HCl ( $\mathrm{pH}$ 8.0) buffer containing $2 \mathrm{mM}$ $\mathrm{MgSO}_{4}, 2 \mathrm{mM}$ DTT, $400 \mathrm{mM}$ sucrose. Total GS activities were determined in Tris- $\mathrm{HCl}(\mathrm{pH} 7.4)$ consisting of $80 \mathrm{mM}$ $\mathrm{MgSO}_{4}, 20 \mathrm{mM}$ sodium glutamate, $20 \mathrm{mM}$ cysteine, $2 \mathrm{mM}$ ethylene glycol tetraacetic acid (EGTA), and $80 \mathrm{mM}$ hydrochloric acid hydroxylamine. The reaction was terminated at $37{ }^{\circ} \mathrm{C}$ after $30 \mathrm{~min}$ by adding acidic $\mathrm{FeCl}_{3}$ solution $\left(370 \mathrm{mM} \mathrm{FeCl}_{3}, 600 \mathrm{mM} \mathrm{HCl}\right.$, and $200 \mathrm{mM}$ trichloroacetic acid). The mixture was left for $10 \mathrm{~min}$ to allow the colour to develop, and then centrifuged at $15000 \mathrm{~g}$ at room temperature for $10 \mathrm{~min}$. The supernatant was then transferred from each well into a new tube and the absorbance at $540 \mathrm{~nm}$ was measured (Yang et al. 2014).

Statistical analysis: The experiment was arranged in a completely randomized design with four replicates and the whole experiment was repeated twice. All experimental data were analyzed by ANOVA using SPSS v. 17.0 software (SPSS Inc, Chicago, IL, USA). Significant differences were tested using the least significant difference (LSD) test at $P<0.05$.

\section{Results}

Salt stress decreased stem length and lateral root number of $G$. uralensis seedlings compared with control. The addition of $0.025 \mathrm{mM}$ or $0.05 \mathrm{mM}$ MeJA markedly increased root length compared with control or $\mathrm{NaCl}$ alone. However, $0.025 \mathrm{mM}$ or $0.05 \mathrm{mM}$ MeJA reduced

stem length, root diameter, and stem diameter compared with control or $\mathrm{NaCl}$ alone (Fig 1).

Salt stress significantly decreased POD and CAT activities of $G$. uralensis seedlings compared with control. The addition of $0.025 \mathrm{mM}$ or $0.05 \mathrm{mM}$ MeJA significantly 


\section{YU et al.}

increased POD activity compared with $\mathrm{NaCl}$. However, MeJA reduced CAT activity (Fig. 2A,B).

Salt stress slightly decreased AsA content G. uralensis seedlings and increased MDA content compared with control. But the changes were not significant. The addition of $0.025 \mathrm{mM}$ or $0.05 \mathrm{mM}$ MeJA significantly increased AsA content compared with control or $\mathrm{NaCl}$ alone (Fig. 2C). Only $0.05 \mathrm{mM}$ MeJA significantly increased

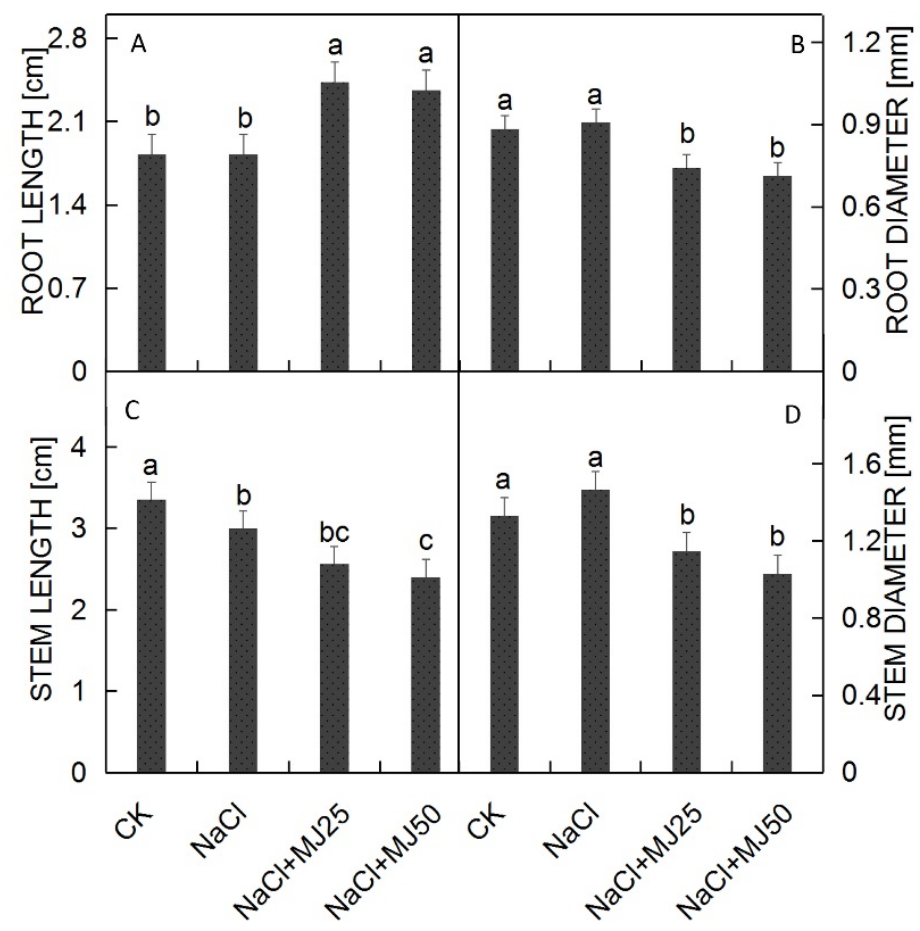

Fig. 1. Effect of MeJA on root length $(A)$, root diameter $(B)$, stem length $(C)$, and stem diameter $(D)$ of Glycyrrhiza uralensis seedlings grown under $100 \mathrm{mM} \mathrm{NaCl}$. Means $\pm \mathrm{SE}, n=6$, the different letters indicate the significant difference at $P \leq 0.05$.

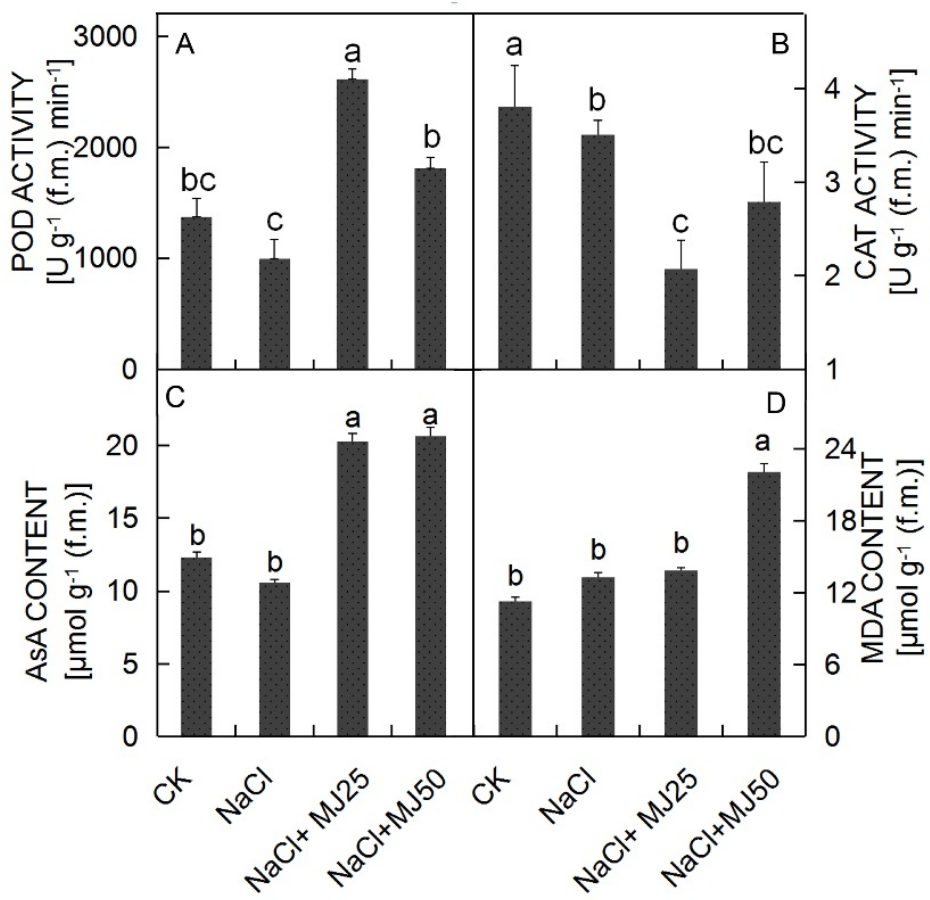

Fig. 2. Effect of MeJA on POD activity (A), CAT activity (B), AsA content $(C)$, and MDA content $(D)$ of $G$. uralensis seedlings grown under $100 \mathrm{mM} \mathrm{NaCl}$. Means $\pm \mathrm{SE}, n=6$, the different letters indicate the significant difference at $P \leq 0.05$. 
MDA content compared with control or $\mathrm{NaCl}$ alone (Fig. 2D).

Salt stress increased the content of $\mathrm{H}_{2} \mathrm{O}_{2}$ and the rate of superoxide production compared with control. The addition of $0.025 \mathrm{mM}$ or $0.05 \mathrm{mM}$ MeJA significantly decreased $\mathrm{H}_{2} \mathrm{O}_{2}$ content compared with $\mathrm{NaCl}$ alone. However, $0.05 \mathrm{mM}$ MeJA increased the production rate of $\mathrm{O}_{2}{ }^{-}$(Fig. 3A, B).

\section{Discussion}

Salinity stress can change most plant physiological and biochemical processes and disturbs normal plant growth and development (Golldack et al. 2014). Faghih et al.
Salt stress slightly reduced GS and NR activities of G. uralensis seedlings compared with control (Fig. 4A). However, salt stress had no significant effect on the activities of SS and SPS compared with control (Fig. 4B,C,D). The addition of $0.025 \mathrm{mM}$ MeJA but not $0.05 \mathrm{mM}$ MeJa enhanced SPS, SS, and NR activities in both salt-stressed and control seedlings. However, both MeJA concentrations inhibited GS activity (Fig. 4A).

(2017) found that exposure to $\mathrm{NaCl}$, especially at high concentrations, reduces the growth of strawberry seedlings. Jiyoung et al. (2009) demonstrated that salt

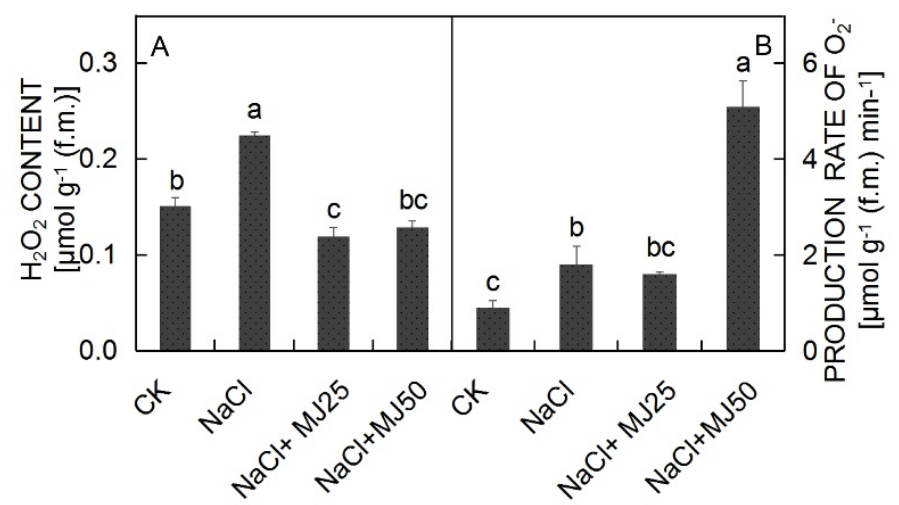

Fig. 3. Effect of MeJA on $\mathrm{H}_{2} \mathrm{O}_{2}$ content $(A)$ and rate of $\mathrm{O}_{2}^{-}$production $(B)$ of G. uralensis seedlings grown under $100 \mathrm{mM} \mathrm{NaCl}$. Means $\pm \mathrm{SE}, n=6$, the different letters indicate the significant difference at $P \leq 0.05$.

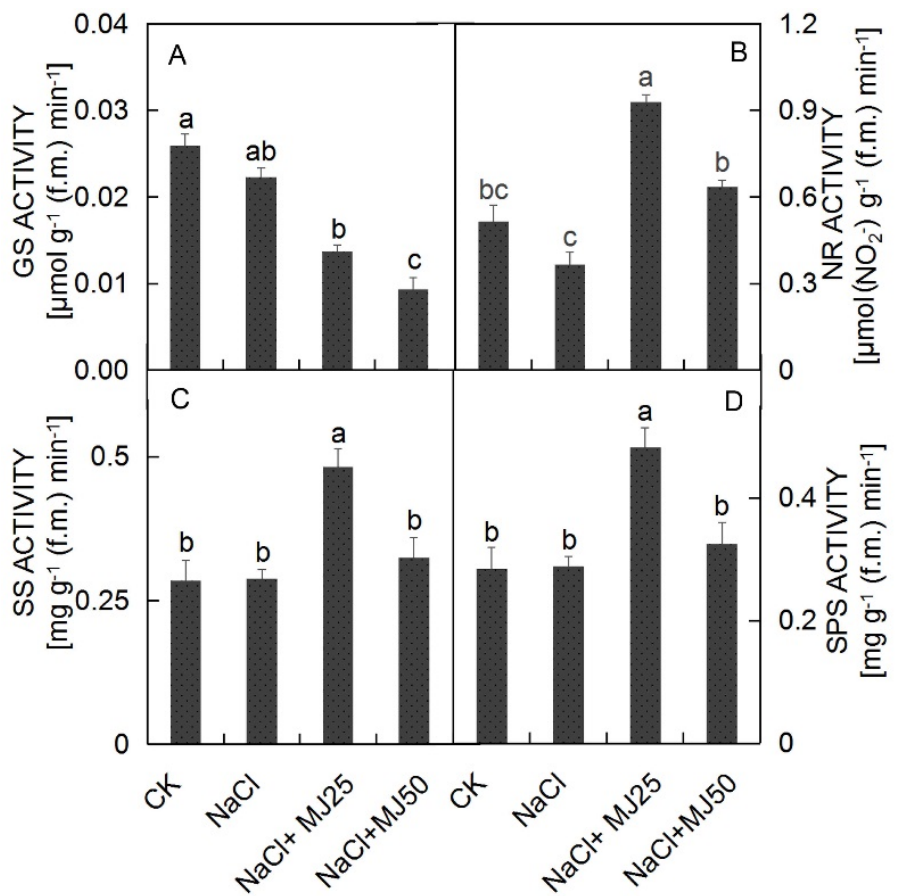

Fig. 4. Effect of MeJA on GS activity (A), NR activity (B), SS activity (C), and SPS activity (D) of G. uralensis seedlings grown under $100 \mathrm{mM} \mathrm{NaCl}$. Means $\pm \mathrm{SE}, n=6$, the different letters within the different treatments indicate the significant difference at $P \leq 0.05$. 
stress significantly reduces soybean growth. Kang et al. (2005) revealed that even low $\mathrm{NaCl}$ concentrations can remarkably decrease the length of rice roots. Our present results showed that compared with the control, treatment with $100 \mathrm{mM} \mathrm{NaCl}$ significantly affected stem length, however, it has no effects on root length, root diameter, and stem diameter. MeJA treatment markedly increased the root length of $G$. uralensis seedlings compared with $\mathrm{NaCl}$ alone (Fig. 1A). In agreement with previously reported results for Robinia pseudoacacia (Jiang et al. 2016), Artemisia annua (Tariq et al. 2011), and strawberry (Faghih et al. 2017), we found that MeJA treatment modified the growth characteristics of $G$. uralensis seedlings. However, MeJA treatment significantly decreased stem length, root diameter, and stem diameter (Fig. 1B,C,D). Given that MeJA treatment also decreases the growth of Pinus sylvestris (Heijari et al. 2005), we hypothesized that the effect of MeJA on salt-stressed plants varies with growth parameter, plant species, and applied concentration of MeJA.

Salt stress can cause the accumulation of ROS, such as $\mathrm{H}_{2} \mathrm{O}_{2}$ and $\mathrm{O}_{2}^{--}$, which cause cellular damage by oxidizing lipids, proteins, and nucleic acids (Golldack et al. 2014, Noctor et al. 2014). MDA is often used as a major indicator of membrane lipid peroxidation, and its content is used to represent the degree of membrane lipid damage (Zhuang et al. 2010). $\quad \mathrm{H}_{2} \mathrm{O}_{2}$ sharply increases during the germination of alfalfa under salt stress (Wang et al. 2009). The $\mathrm{O}_{2}{ }^{--}$and $\mathrm{H}_{2} \mathrm{O}_{2}$ content increases in the leaves and petals of Tagetes erecta under long-term salt stress (Garg and Bhandari 2016). Salt stress increases the MDA content and membrane permeability of Ammodendron bifolium, Gleditsia sinensis (Liu et al. 2014), and G. uralensis plants (Pan et al. 2006). These results are similar to those observed in the present study. Here, we observed that $\mathrm{O}_{2}{ }^{-}$ production rate and $\mathrm{H}_{2} \mathrm{O}_{2}$ content were increased under $100 \mathrm{mM} \mathrm{NaCl}$ (Fig. 3A,B). Treatments with $0.05 \mathrm{mM}$ MeJA attenuated the increase in $\mathrm{O}_{2}^{-}$, but it had no effect on $\mathrm{H}_{2} \mathrm{O}_{2}$ content under both 0.025 or $0.05 \mathrm{mM} \mathrm{NaCl}$ (Fig. $3 A, B)$. These results were similar to those of a previous study showing that MeJA application decreases $\mathrm{O}_{2}^{-}$ content of the roots and leaves of A. annua (Aftab et al. 2011) and of diploid and tetraploid R. pseudoacacia plants (Jiang et al. 2016). The efficient destruction of $\mathrm{H}_{2} \mathrm{O}_{2}$ and $\mathrm{O}_{2}{ }^{--}$in plant cells requires the action of different antioxidants. Salt stress alters enzyme activities involved in ROS scavenging (Hernandez et al. 2000, Sreenivasulu et al. 2000). In the current study, we found that the highest rate of POD activity occurred under $0.025 \mathrm{mM}$ MeJA treatment and that POD activity slightly decreased under $0.05 \mathrm{mM}$ MeJA treatment (Fig. 2A). These results indicated that the changes of POD activity depended on MeJA concentration. These results indicated that the changes of POD activity depended on MeJA concentration. Parida and Das (2005) reported that POD is one of the most important enzymes in $\mathrm{H}_{2} \mathrm{O}_{2}$ degradation. CAT catalyzes the direct decomposition of $\mathrm{H}_{2} \mathrm{O}_{2}$ into water and oxygen, does not require reducing power, and exhibits a high reaction rate. Consistent with the results of Pan et al. (2006), we found that CAT activity significantly declined in $G$. uralensis seedlings treated with 0.025 or $0.05 \mathrm{mM}$ MeJA (Fig. 2B). Non-enzymatic antioxidant, such as AsA, cooperate with antioxidant enzymes to maintain the integrity of photosynthetic membranes under oxidative stress. Koffler et al. (2015) found that the AsA content of salt-stressed Arabidopsis plants decreased over time. In the present study, we found that the AsA content in salt-stressed $G$. uralensis seedlings was only slightly lower than in control seedlings and 0.025 or $0.05 \mathrm{mM}$ MeJA markedly increased AsA content (Fig. 2C).

Salt stress alters a wide array of processes, such as carbon and nitrogen metabolism. Salinity decreases the nitrogen content of the roots and stems of Sesbania sp. and the total nitrogen content of alfalfa (Chakrabarti and Mukherji 2003). Salt stress also depresses carbon metabolism, ultimately decreasing energy and sugar production (Cuellar-Ortiz et al. 2008). Sucrose synthase plays an important role in phloem loading and unloading and SPS catalyzes the synthesis of sucrose phosphate during the last step of dark $\mathrm{CO}_{2}$ fixation in plant tissues (Azevedo-Neto et al. 2004). Nitrate reductase reduces $\mathrm{NO}_{3}{ }^{-}$taken up by plant roots from soil to $\mathrm{NO}_{2}{ }^{-}$in the cytosol. $\mathrm{NH}_{4}^{+}$is converted to glutamate by GS. MeJA promotes the transcription of numerous genes that can affect the plant resource allocation (Hanik et al. 2010). For example, MeJA increased $\mathrm{C}: \mathrm{N}$ ratio in tomato leaves (Gómez et al. 2010). In the present study, we found that salt stress nonsignificantly decreased the activities of NR and GS in G. uralensis seedlings and has no effects on the activities of SPS and SS; these effects are specific responses to salt stress and constitute a strategy for maintaining balanced sucrose content under stress conditions. In salt-stressed $G$. uralensis seedlings, $0.025 \mathrm{mM}$ MeJA treatment significantly up-regulated the activities of NR, SS, and SPS but inhibited activity of GS (Fig. 4). These results indicated that MeJA may alleviate the damage of salt-stressed plant through regulating sucrose synthesis and metabolism for maintaining normal growth under stress conditions. However, more research is need to clarify this effect.

In conclusion, MeJA treatment alleviated oxidative stress through enhancing the activity of ROS scavenging enzyme POD and content of non-enzymatic antioxidant AsA content and by strengthening carbon and nitrogen metabolism enzyme activities (NR, SPS, and SS) at its lower $(0.025 \mathrm{mM})$ concentration. 


\section{References}

Abdelhamid, M., Rady, M.M., Osman, A.S., Abdalla, M.A.: Exogenous application of proline alleviates salt-induced oxidative stress in Phaseolus vulgaris L. plants. - J. hort. Sci. Biotechnol. 88: 439-446, 2015.

Aftab, T., Khan, M.M., Idrees, M., Naeem, M., Moinuddin., Hashmi, N.: Methyl jasmonate counteracts boron toxicity by preventing oxidative stress and regulating antioxidant enzyme activities and artemisinin biosynthesis in Artemisia annua L. - Protoplasma 248: 601-612, 2011.

Azevedo-Neto, A.D., Prisco, J.T., Enéas-Filho, J., Lacerda, C.F., Silva, J.V., Costa PHA.: Effects of salt stress on plant growth, stomatal response and solute accumulation of different maize genotypes. - Braz. J. Plant Physiol. 16: 31-38, 2004.

Chakrabarti, N., Mukherji, S.: Effect of phytohormone pretreatment on nitrogen metabolism in Vigna radiata under salt stress. - Biol. Plant. 46: 63-66, 2003.

Chawla, S., Jain, S., Jain, V.: Salinity induced oxidative stress and antioxidant system in salt-tolerant and salt-sensitive cultivars of rice (Oryza sativa L.). - J. Plant Biochem. Biotech. 22: 27-34. 2013.

Cuellar-Ortiz, S.M., De, L.P., Acosta-Gallegos, J., Covarrubias, A.A.: Relationship between carbohydrate partitioning and drought resistance in common bean. - Plant Cell Environ. 31: 1399-1409, 2008.

Eraslan, F., Inal, A., Gunes, A., Alpaslan, M.: Impact of exogenous salicylic acid on the growth, antioxidant activity and physiology of carrot plants subjected to combined salinity and boron toxicity. - Sci. Horticult. 113: 120-128, 2007.

Faghih, S., Ghobadi, C., Zarei, A.: Response of strawberry plant cv. 'camarosa' to salicylic acid and methyl jasmonate application under salt stress condition. - J. Plant Growth Regul. 36: 1-9, 2017.

Garg, N., Bhandari, P.: Silicon nutrition and mycorrhizal inoculations improve growth, nutrient status, $\mathrm{K}^{+} / \mathrm{Na}^{+}$ratio and yield of Cicer arietinum L. genotypes under salinity stress. - Plant Growth Regul. 78: 371-387, 2016.

Golldack, D., Li, C., Mohan, H., Probst, N.: Tolerance to drought and salt stress in plants: unraveling the signaling networks. Front. Plant Sci. 5: 151-160, 2014.

Gómez, S., Ferrieri, R.A., Schueller, M., Orians, C.M.: Methyl jasmonate elicits rapid changes in carbon and nitrogen dynamics in tomato. - New Phytol. 188: 835-844, 2010.

Gunes, A., Inal, A., Alpaslan, M., Eraslan, F., Bagci, E.G., Cicek, N.: Salicylic acid induced changes on some physiological parameters symptomatic for oxidative stress and mineral nutrition in maize ( Zea mays L.) grown under salinity. - J. Plant Physiol. 164: 728-736, 2007.

Gumerova, E.A., Akulov, A.N., Rumyantseva, N.I.: Effect of methyl jasmonate on growth characteristics and accumulation of phenolic compounds in suspension culture of tartary buckwheat. - Russ. J. Plant Physiol. 62: 195-203, 2015.

Hanik, N., Gómez, S., Best, M., Schueller, M., Orians, C.M., Ferrieri, R.A.: Partitioning of new carbon as $11 \mathrm{C}$ in Nicotiana tabacum reveals insight into methyl jasmonate induced changes in metabolism. - J. chem. Ecol. 36: 1058$1067,2010$.

Heijari, J., Nerg, A.M., Kainulainen, P., Viiri, H., Vuorinen, M., Holopainen, J.K.: Application of methyl jasmonate reduces growth but increases chemical defence and resistance against
Hylobius abietis in Scots pine seedlings. - Entomol. Exp. Appl. 115: 117-124, 2005.

Hernández, J.A., Jiménez, A., Mullineaux, P., Sevilia, F.: Tolerance of pea (Pisum sativum L.) to long-term salt stress is associated with induction of antioxidant defences. - Plant Cell Environ. 23: 853-862, 2000.

Ji, Y.Y., Hamayun, M., Lee, S.K., Lee, I.J.: Methyl jasmonate alleviated salinity stress in soybean. - J. Crop Sci. 12: 63-68, 2009.

Jiang, M., Xu, F., Peng, M., Huang, F., Meng, F.: Methyl jasmonate regulated diploid and tetraploid black locust (Robinia pseudoacacia L.) tolerance to salt stress. - Acta Physiol. Plant. 38: 1-13, 2016.

Jiyoung, Y., Hamayun, M., Sukyung, L., Injung, L.: Methyl jasmonate alleviated salinity stress in soybean. - J. Crop Sci. Biotechnol. 12: 63-68, 2009

Kang, D.J, Seo, Y.J., Lee, J.D., Ishii, R., Kim, U., Shin, D.H.: Jasmonic acid differentially affects growth, ion uptake and abscisic acid concentration in salt-tolerant and salt-sensitive rice cultivars. - J. Agron. Crop. Sci. 191: 273-282, 2005.

Koffler, B.E., Luschin-Ebengreuth, N., Zechmann, B.: Compartment specific changes of the antioxidative status in Arabidopsis thaliana during salt stress. - J. Plant Biol. 58: 8$16,2015$.

Li, H.L., Zhu, Y.X., Hu, Y.H., Han, W.H., Gong, H.J.: Beneficial effects of silicon in alleviating salinity stress of tomato seedling grown under sand culture. - Acta Physiol. Plant. 37: $1-9,2015$.

Liu, J., Xia, J., Fang, Y., Li, T., Liu, J.: Effects of salt-drought stress on growth and physiobiochemical characteristics of Tamarix chinensis seedlings. - Sci. World. J. 6: 7-21, 2014.

Moons, A., Montagu, M.V.: Antagonistic effects of abscisic acid and jasmonates on salt stress-inducible transcripts in rice roots. - Plant Cell 9: 2243-2259, 1997.

Noctor, G., Mhamdi, A., Foyer, C.H.: The roles of reactive oxygen metabolism in drought: not so cut and dried. - Plant Physiol. 164: 1636-1648, 2014.

Pan, Y., Wu, L.J, Yu, Z.L.: Effect of salt and drought stress on antioxidant enzymes activities and sod isoenzymes of liquorice (Glycyrrhiza uralensis Fisch). - Plant Growth Regul. 49: 157-165, 2006.

Parida, A.K., Das, A.B.: Salt tolerance and salinity effects on plants: a review. - Ecotox. Environ. Safety 60: 324-349, 2005.

Schrofelbauer, B., Raffetseder, J., Hauner, M., Wolkerstorfer, A., Ernst, W., Szolar, O. H.: Glycyrrhizin, the main active compound in liquorice, attenuates pro-inflammatory responses by interfering with membrane-dependent receptor signalling. - Biochem. J. 421: 473-482, 2009.

Slama, I., Abdelly, C., Bouchereau, A., Flowers, T., Savouré, A.: Diversity, distribution and roles of osmoprotective compounds accumulated in halophytes under abiotic stress. Ann. Bot. 115: 433-447, 2015.

Sohn, Y.G., Lee, B.H., Kang, K.Y., Lee, J.J.: Effects of $\mathrm{NaCl}$ stress on germination, antioxidant responses, and proline content in two rice cultivars. - J. Plant Biol. 48: 201-208, 2005.

Sreenivasulu, N., Grimm, B., Wobus, U., Weschke, W.: Differential response of antioxidant compounds to salinity stress in salt-tolerant and salt-sensitive seedlings of foxtail millet (Setaria italica). - Physiol. Plant. 109: 435-442, 2000. 
Tariq, A., Masroor, M., Khan, A., Mohd, I., Naeem, M., Moinuddin, I., Nadeem, H.: Methyl jasmonate counteracts boron toxicity by preventing oxidative stress and regulating antioxidant enzyme activities and artemisinin biosynthesis in Artemisia annua L. - Protoplasma 248: 601-612, 2011.

Walia, H., Wilson, C., Wahid, A., Condamine, P., Cui, X., Close, T.J.: Expression analysis of barley (Hordeum vulgare L.) during salinity stress. - Funct. integr. Genomic 6: 143-156, 2006.

Wang, W.B., Kim, Y.H., Lee, H.S., Kim, K.Y., Deng, X.P., Kwak, S.S.: Analysis of antioxidant enzyme activity during germination of alfalfa under salt and drought stresses. - Plant Physiol. Biochem. 47: 570-577, 2009.

Wang, H., Zhang, M., Rui, G., Shi, D., Bao, L., Lin, X.: Effects of salt stress on ion balance and nitrogen metabolism of old and young leaves in rice (Oryza sativa L.). BMC Plant Biol. 12: 194-205, 2012.

Wasternack, C., Hause, B.: Jasmonates and octadecanoids: signals in plant stress responses and development. - Progr. Nucl. Acid Res. mol. Biol. 72: 165-221, 2002.

Wasternack, C.: Action of jasmonates in plant stress responses and development - applied aspects. - Biotechnol. Adv. 32: 31-39, 2014.

Wutipraditkul, N., Wongwean., Buaboocha, T.: Alleviation of salt-induced oxidative stress in rice seedlings by proline and/or glycinebetaine. - Biol. Plant. 59: 547-553, 2015.

Wolucka, B.A., Goossens, A.D.: Methyl jasmonate stimulates the de novo biosynthesis of vitamin $\mathrm{C}$ in plant cell suspensions. - J. exp. Bot. 56: 25-27, 2005.

Yang, X.H., Li, J.M., Dong, X.H., Duan, L.S., Li, Z.H.: [Effects of salt stress on growth and some physiological indexes in Glycyrrhiza uralensis Fisch seedlings.] - Acta agr. borealisin. 21: 39-42, 2006. [In Chinese]

Yang, B., Wang, X.M., Ma, H.Y., Jia, Y., Li, X., Dai, C.C.: Effects of the fungal endophyte Phomopsis liquidambari on nitrogen uptake and metabolism in rice. - Plant Growth Regul. 73: 165-179, 2014.

Zhang, W., Cao, Z., Xie, Z., Lang, D., Zhou, L., Chu, Y.: Effect of water stress on roots biomass and secondary metabolites in the medicinal plant Stellaria dichotoma L. var. lanceolata. - Sci. Hort. 224: 280-285, 2017.

Zhang, X., Xiong, T.: Improving Glycyrrhiza uralensis, salt tolerance with $\mathrm{N}^{+}$ion irradiation. - Russ. J. Plant Physiol. 55: 344-349, 2008.

Zhou, Y.H., Yu, J.Q., Huang, L.F., Nogués, S.: The relationship between $\mathrm{CO}_{2}$ assimilation, photosynthetic electron transport and water-water cycle in chill-exposed cucumber leaves under low light and subsequent recovery. - Plant Cell Environ. 27: 10.053-1514, 2004.

Zhuang, W.W., Li, J., Cao, M.H., Feng, W.J., Li, Y.P.: [Effects of salt-drought intercross stress on physiological and biochemical characteristics of Ammodendron argenteum (Pall.) Kuntze seedlings.] - J. Wuhan. Bot. Res. 28: 730-736, 2010. [In Chinese] 